Aim of the study: Oral cancer ranks in the top three of all cancers in India and is quickly becoming a global health priority. More than $90 \%$ of oral and oropharyngeal cancers are squamous cell carcinoma. The purpose of this study was to document its incidence depending upon the involvement of different sites of oral cavity, and its variation with age and gender. Material and methods: Histopathologically proven oral squamous cell carcinoma cases were collected from the department of oral and maxillofacial surgery RDC, PIMS. The cases were systematically grouped under three headings: anatomical sub-site of oral cavity, age group, and gender, which were analysed to calculate the prevalence of oral cancer. The study was undertaken after obtaining approval from the institutional Ethical Committee board.

Results: Among the different sites of oral cavity, the highest incidence (31.47\%) of oral squamous cell carcinoma was seen for buccal mucosa in our study. The most affected age group $(39.50 \%)$ were patients above 50 years old, predominantly involving males.

Conclusions: The population in this study were mostly from remote areas, among which a high rate of occurrence of oral cancer was encountered because the people were of low socio-economic class, had a casual attitude towards their health, high rate of tobacco consumption, and limited health care facilities. This study provides valuable data of the prevalence of oral cancer among the rural population.

Key words: squamous cell carcinoma, prevalence, buccal mucosa, oral cavity, gingivo-buccal carcinoma.

Contemp Oncol (Pozn) 2017; 21 (2): 178-183 DOI: https://doi.org/10.5114/wo.2017.68628

\section{The prevalence of squamous cell carcinoma in different sites of oral cavity at our Rural Health Care Centre in Loni, Maharashtra - a retrospective 10 -year study}

\author{
Parul Tandon, Anuj Dadhich, Harish Saluja, Shilpa Bawane, \\ Shivani Sachdeva
}

Rural Dental College, Pravara Institute of Medical Sciences, Loni, Maharashtra, India

\section{Introduction}

Oral cancers are malignant neoplasms that affect the structures or tissues of the mouth. They may be a primary lesion that originates in the mouth, a metastasis from a distant site, or an extension from an adjoining site. Of these oral cancers, more than $90 \%$ are squamous cell carcinomas arising in the mucous membranes of the mouth and oropharynx [1].

It is an important global health concern accounting for an estimated 275,000 cases and 128,000 deaths annually [1]. Its incidence varies markedly by geographic region, and more than half of all cancer cases occur in developing countries [2]. India has one of the highest incidences of oral cancer and accounts for about 30\% of all new cases annually [3]. A recent survey of cancer mortality in India shows cancer of the oral cavity as the leading cause of mortality in men, and it is responsible for $22.9 \%$ of cancer-related deaths [4].

India is a high-risk region for oral and oro-pharyngeal cancer due to a high prevalence of tobacco use, particularly chewing (in both sexes), smoking, and alcohol drinking in the male population [5]. Apart from tobacco and alcohol, dietary factors, human papilloma virus (HPV) infection, genetic factors, and oral hygiene are reported as risk factors as well [4]. Social inequalities are related to oral cavity cancers, a risk linked to factors directly affecting behaviour and lifestyle. The aim of this study was to describe the prevalence of oral squamous cell carcinoma (OSCC) at our institute situated in the rural area, Loni, Maharashtra over a period of 10 years.

\section{Material and methods}

The archive of the Department of Oral and Maxillofacial surgery of Pravara Institute of Medical Sciences, Loni, Maharashtra was reviewed from Jan 2003 to Dec 2013. Total of 1020 patients with biopsy-proven squamous cell carcinoma of the oral cavity and oropharynx were selected in this study. Patients with salivary gland tumours and those not willing to undergo biopsy were excluded from this study.

Cases were divided into 11 different anatomical sites of oral cavity, i.e. buccal mucosa, buccal mucosa with skin, tongue, floor of mouth, mandibular alveolus, retromolar trigone, gingivo-buccal sulcus, maxillary alveolus, palate, upper/ lower lip, and peritonsilar region. The prevalence of OSCC was calculated in the above-mentioned anatomical sites along with the variation of occurrence of cancer in these sites as per different age groups, ranging from $<20$ years of age to $>50$ years of age and gender was evaluated. This study followed the Declaration of Helsinki on medical protocol and ethics, and the regional Ethical Review Board of Rural Dental College, PIMS, Loni, approved the study. 


\section{Results}

The highest peak of prevalence of OSCC (39.50\%) in our study was observed in the age group of above 50 years ( $\mathrm{Ta}$ ble 1). In our study, comparing among all the anatomical sites of the oral cavity, buccal mucosa was found to be the most commonly affected (31.4\%) (Table 2). Out of a total of 321 cases of carcinoma of buccal mucosa, 191 (59.5\%) were males and 130 (40.4\%) were females. The most predominant age group that was seen to be affected by buccal mucosa cancer were those $>50$ years of age (Table 3 ). The second most common site observed in our study for oral cavity cancer was the mandibular alveolus (21.5\%). Out of a total of 220 patients of carcinoma of mandibular alveolus, 138 (62.8\%) were males and 82 (37.2\%) were females; patients more than 50 years of age were the most frequently affected (Table 4). The third most commonly affected anatomical site involved by cancer was observed to be the tongue (19.21\%). Out of a total of 196 patients, 155 (79\%) were found to be males and 41 (20.9\%) were females. Patients in the age group 21-30 years were the population most frequently affected by tongue cancers, unlike the above two sites (Table 5). Carcinoma of the buccal vestibule was the fourth most common site observed in our study (8.82\%). Out of a total of 90 cases of buccal vestibule carcinoma, 54 (60\%) were males and 36 (40\%) were females, and the most affected age group was patients above 50 years of age (Table 6). 5.29\% cases of palatal carcinomas were registered in our study and calculated to be the fifth most commonly encountered carcinomas. Out of a total of 54 cases of palatal carcinomas, 33 (61.1\%) were seen in males and 21 (38.8\%) in females. The population in the age group of more than 50 years were observed to be most commonly affected ones (Table 7). The sixth most common site involved by cancer was maxillary alveolus, seen in 45 cases of oral cancer, among which the predominance was observed in 27 (60\%) females, and the remaining 18 (40\%) cases were found in males. The most commonly encountered population regarding this site were the patients of age group more than 50 years (Table 8). Carcinoma of the retromolar trigone was the seventh most commonly encountered anatomical site in this study, in which out of a total of 28 patients, 22 (78.5\%) were males and 6 (21.4\%) were females, and patients in the age group of 31-40 years were most commonly affected (Table 9). Twenty-four patients of oral carcinoma were affected by cancer of the lips (most frequently the lower lip), among which 18 (75\%) were seen in males and 6 (25\%) were found in females. The age group 41-50 years was the most common age group affected by carcinoma of the

Table 5. Variation in distribution of tongue carcinoma according to age group and gender

\begin{tabular}{|cccc|}
\hline Age (years) & Males $n(\%)$ & Females $n(\%)$ & Total $n(\%)$ \\
\hline $20-30$ & $13(6.6)$ & $8(4.0)$ & $21(10.7)$ \\
\hline $31-40$ & $53(27.0)$ & $12(6.1)$ & $65(33.2)$ \\
\hline $41-50$ & $38(19.3)$ & $11(5.6)$ & $49(25.0)$ \\
\hline 50 & $51(26.0)$ & $10(5.1)$ & $61(31.1)$ \\
\hline Total & $155(79.0)$ & $41(20.9)$ & $196(100)$ \\
\hline
\end{tabular}

Table 1. Prevalence of oral cancer in different age groups

\begin{tabular}{ccc|}
$\begin{array}{c}\text { Age of patient } \\
\text { (years) }\end{array}$ & $\begin{array}{c}\text { Number of patients } \\
(n=1020)\end{array}$ & $\%$ of patients \\
\hline 20 & 2 & 0.19 \\
\hline $20-30$ & 114 & 11.17 \\
$31-40$ & 129 & 24.41 \\
$41-50$ & 252 & 24.70 \\
$>50$ & 403 & 39.50 \\
\hline
\end{tabular}

Table 2. Prevalence of oral squamous cell carcinoma in various sites of oral cavity

\begin{tabular}{|lcc|}
\hline $\begin{array}{l}\text { Different sites } \\
\text { of oral cavity }\end{array}$ & $\begin{array}{c}\text { Number of patients } \\
(n=1020)\end{array}$ & $\%$ of patients \\
\hline Buccal mucosa & 321 & 31.47 \\
\hline Mandibular alveolus & 220 & 21.50 \\
\hline Tongue & 196 & 19.21 \\
\hline Buccal vestibule & 90 & 8.82 \\
\hline Palate & 54 & 5.29 \\
\hline Maxillary alveolus & 45 & 4.41 \\
\hline Retromolar region & 28 & 2.74 \\
\hline Lip & 24 & 2.35 \\
\hline Floor of mouth & 24 & 2.35 \\
\hline Buccal mucosa with & 9 & 0.80 \\
\hline skin & 9 & 0.80 \\
\hline Peritonsillar region & & \\
\hline
\end{tabular}

Table 3. Variation in distribution of buccal mucosa carcinoma according to age group and gender

\begin{tabular}{cccc} 
Age (years) & Males $n(\%)$ & Females $n(\%)$ & Total $n(\%)$ \\
$<20$ & $2(0.6)$ & - & $2(0.6)$ \\
\hline $20-30$ & $30(9.3)$ & $21(6.5)$ & $51(15.8)$ \\
\hline $31-40$ & $45(14.0)$ & $33(10.2)$ & $78(24.3)$ \\
$41-50$ & $52(16.2)$ & $27(8.4)$ & $79(24.6)$ \\
\hline 50 & $62(19.3)$ & $49(15.2)$ & $111(34.6)$ \\
\hline Total & $191(56.5)$ & $130(40.4)$ & $321(100)$ \\
\hline
\end{tabular}

Table 4. Variation in distribution of mandibular alveolus carcinoma according to age group and gender

\begin{tabular}{cccc|}
\hline Age (years) & Males $n(\%)$ & Females $n(\%)$ & Total $n(\%)$ \\
\hline $20-30$ & $13(5.9)$ & $11(5.0)$ & $24(10.9)$ \\
$31-40$ & $35(15.9)$ & $25(11.3)$ & $60(27.2)$ \\
$41-50$ & $28(12.7)$ & $19(8.6)$ & $47(21.3)$ \\
$>50$ & $62(28.2)$ & $27(12.2)$ & $99(45.0)$ \\
\hline Total & $138(62.8)$ & $82(37.2)$ & $220(100)$ \\
\hline
\end{tabular}

Table 6. Variation in distribution of Buccal vestibule carcinoma according to age group and gender

\begin{tabular}{cccr|}
\hline Age (years) & Males $n(\%)$ & Females $n(\%)$ & Total $n(\%)$ \\
\hline $20-30$ & $6(6.6)$ & $5(5.5)$ & $11(12.2)$ \\
\hline $31-40$ & $8(8.8)$ & $5(5.5)$ & $13(14.4)$ \\
\hline $41-50$ & $16(17.7)$ & $11(12.2)$ & $27(30.0)$ \\
\hline 50 & $24(26.6)$ & $15(16.6)$ & $39(43.3)$ \\
\hline Total & $54(60.0)$ & $36(40.0)$ & $90(100.0)$
\end{tabular}


Table 7. Variation in distribution of palatal carcinoma according to age group and gender

\begin{tabular}{|cccc|}
\hline Age (years) & Males $n(\%)$ & Females $n(\%)$ & Total $n(\%)$ \\
\hline $20-30$ & - & - & $21(10.7)$ \\
\hline $31-40$ & $8(14.8)$ & $4(7.4)$ & $12(22.2)$ \\
\hline $41-50$ & $7(12.9)$ & $5(9.2)$ & $12(22.2)$ \\
\hline 50 & $18(33.3)$ & $12(22.2)$ & $30(55.5)$ \\
\hline Total & $33(61.1)$ & $21(38.8)$ & $54(100)$ \\
\hline
\end{tabular}

Table 8. Variation in distribution of maxillary alveolus carcinoma according to age group and gender

\begin{tabular}{cccc}
\hline Age (years) & Males $n(\%)$ & Females $n(\%)$ & Total $n(\%)$ \\
\hline $20-30$ & $4(8.8)$ & $2(4.4)$ & $6(13.3)$ \\
$31-40$ & $2(4.4)$ & $1(2.2)$ & $3(6.6)$ \\
\hline $41-50$ & $4(8.8)$ & $2(4.4)$ & $6(13.3)$ \\
$>50$ & $20(44.4)$ & $10(22.2)$ & $30(66.6)$ \\
\hline Total & $27(60.0)$ & $18(40.0)$ & $45(100)$ \\
\hline
\end{tabular}

Table 9. Variation in distribution of retromolar region carcinoma according to age group and gender

\begin{tabular}{|cccc} 
Age (years) & Males $n(\%)$ & Females $n(\%)$ & Total $n(\%)$ \\
\hline $20-30$ & - & - & - \\
\hline $31-40$ & $7(25.0)$ & $2(7.1)$ & $9(32.1)$ \\
\hline $41-50$ & $10(35.7)$ & $1(3.5)$ & $11(39.2)$ \\
\hline 50 & $5(17.8)$ & $3(10.7)$ & $8(28.5)$ \\
\hline Total & $22(78.5)$ & $6(21.4)$ & $28(100)$
\end{tabular}

Table 10. Variation in distribution of lip carcinoma according to age group and gender

\begin{tabular}{|cccc|}
\hline Age (years) & Males $n(\%)$ & Females $n(\%)$ & Total $n(\%)$ \\
\hline $20-30$ & $1(4.1)$ & - & $1(4.1)$ \\
\hline $31-40$ & $7(29.1)$ & $2(8.3)$ & $9(37.5)$ \\
$41-50$ & $5(20.8)$ & $3(12.5)$ & $8(33.23)$ \\
\hline 50 & $5(20.8)$ & $1(4.1)$ & $6(25.0)$ \\
\hline Total & $18(75.0)$ & $6(25.0)$ & $24(100)$ \\
\hline
\end{tabular}

Table 11. Variation in distribution of floor of mouth carcinoma according to age group and gender

\begin{tabular}{cccc}
\hline Age (years) & Males $n(\%)$ & Females $n(\%)$ & Total $n(\%)$ \\
\hline $20-30$ & - & - & - \\
\hline $31-40$ & - & - & - \\
\hline $41-50$ & $9(37.5)$ & - & $9(37.5)$ \\
\hline 50 & $15(62.5)$ & - & $15(62.5)$ \\
\hline Total & $24(100)$ & - & $24(100)$
\end{tabular}

Table 12. Variation in distribution of buccal mucosa carcinoma with skin involvement according to age group and gender

\begin{tabular}{cccc} 
Age (years) & Males $n(\%)$ & Females $n(\%)$ & Total $n(\%)$ \\
\hline $20-30$ & - & - & - \\
$31-40$ & - & - & - \\
$41-50$ & $3(33.3)$ & $1(11.1)$ & $4(44.4)$ \\
$>50$ & $3(33.3)$ & $2(22.2)$ & $5(55.5)$ \\
Total & $6(66.6)$ & $3(33.3)$ & $9(100)$
\end{tabular}

lips in our study (Table 10). Twenty-four patients (2.35\%) of oral carcinoma were found to have involvement of the floor of the mouth, with all of them (100\%) male, and most commonly from the population more than 50 years of age (Table 11$)$. In total nine $(0.8 \%)$ cases were seen with the involvement of skin along with buccal mucosa, among which six $(66.6 \%)$ were males and three (33.3\%) were females, and the population under the age group of more than 50 years were the most commonly encountered group (Table 12). Carcinoma of the peritonsillar region was seen to be involved in $0.8 \%$ of the total cases of oral cancer. In total six (66.6\%) males and three (33.3\%) females were found to be affected by peritonsillar cancer, and all of the cases nine $(100 \%)$ were seen in patients more than 50 years of age (Table 13 ).

\section{Discussion}

The aim of this study was to represent the prevalence of oral squamous cell carcinoma among in-patients for a period of 10 years (2003-2013) at our institute in a rural city and to examine the variation of occurrence of oral cancer in different anatomical sub-sites of oral cavity along with the frequently affected age groups and gender as per the location of cancer in the mouth.

This variation of age group and gender involvement in different sites of oral cavity contains valuable clues regarding the causes and biological mechanism of development of the disease.

Our study comprised 1020 patients, out of which 602 (59.01\%) were males and 418 (40.98\%) were females. The sex differences in oral cancer may largely reflect different cultural behaviour and lifestyle factors among the population. Worldwide, the incidence of head and neck cancer is higher for males than for females [6-10]. This may be because of the greater indulgence of men in the risk factors.

About $75 \%$ of oral cancer is attributable to tobacco use and alcohol consumption [11, 12]. Regardless of the different modalities of tobacco consumption (cigarettes, cigars, pipes, chewing tobacco, or snuff), its use is more strongly associated with oral cancer than alcohol alone. High levels of carcinogenic tobacco-specific nitrosamines, e.g. nitroso-nor-nicotine (NNN) and 4-methyl-nitrosamino-1-(3 pyridyl)-1-butanone (NNK) were reported in the saliva of oral snuff users in the Sudan [13] and tobacco chewers in India [14]. Chewing of the areca nut (betel quid) releases large amounts of reactive oxygen species, especially while the quid is present in the oral cavity. Both tobacco specific nitrosamines and reactive oxygen species are major genotoxic agents involved in oral cancer associated with the use of chewing tobacco [15].

Table 13. Variation in distribution of peritonsillar region carcinoma according to age group and gender

\begin{tabular}{|cccc|}
\hline Age (years) & Males $n(\%)$ & Females $n(\%)$ & Total $n(\%)$ \\
\hline $20-30$ & - & - & - \\
\hline $31-40$ & - & - & - \\
\hline $41-50$ & - & - & - \\
\hline 50 & $6(66.6)$ & $3(33.3)$ & $9(100)$ \\
\hline Total & $6(66.6)$ & $3(33.3)$ & $9(100)$ \\
\hline
\end{tabular}


People who use both alcohol and tobacco are atespecially high risk of developing oral cancer due to synergistic effects [16] because the dehydrating effect of alcohol on cell membranes enhances the ability of tobacco-associated carcinogens to permeate the mouth tissues; in addition, nutritional deficiencies associated with heavy drinking can lower the body's natural ability to use antioxidants to prevent the formation of cancer [17]. In our study, the most common risk factor observed was different forms of tobacco (smokeless/chewing tobacco as well as cigarette smoking) and alcohol drinking.

The occurrence of oral cancer increases with age in all parts of the world. It is usually a disease that occurs after the fifth decade of life [18-22]. The mean age at presentation is in the fifth and early sixth decades in the Asian population. This is in accordance with our study, in which the peak prevalence of OSCC (39.50\%) was observed in the age group of above 50 years. This is because the relative risk of cancer increases in relation to age [23]. According to Phillips et al. in 1987, it was widely believed that a 25-year latency exists between the initial exposure to a carcinogen and the development of a clinically recognisable cancer [24]. The WHO in 1987 stated that OSCC is rare in patients aged 40 years and younger [25]; however, an alarming increase in the incidence of oral cancers among the younger generation has been reported from many parts of the world [26-29], a trend that appears to be continuing. A high incidence of OSCC was reported between the age groups of 30-50 years according to our data. This was because of indulgence in customary habits at a very young age. A study performed in Southern England concluded that a substantial proportion of cases of oral cancer in younger people occurred in the absence of, or relatively short duration of, exposure to traditional risk factors [30-32]. This suggests that factors other than tobacco and alcohol are implicated in the development of oral cancer in a significant minority of cases. Hereditary predisposition in younger patients, family history, and HPV infection also contribute to the rise in OSCC $[28,33,34]$.

In India, the gingivo-buccal complex (alveolar ridge, gingival-buccal sulcus, buccal mucosa) forms the most common sub-site for cancer of the oral cavity [35], in contrast to the tongue and floor of the mouth that is more common in the western world $[36,37]$. This difference can be correlated with tobacco consumption habits. In India smokeless tobacco exposure is common as compared to the smoked version in the West. Traditionally, the paan is placed in the gingival-buccal sulcus and often retained for a prolonged duration, which is responsible for the high prevalence of gingivo-buccal cancer [38]. In our study, $31.47 \%$ of the population were seen with the involvement of buccal mucosa, the most common anatomical site recorded according to our data. This is in accordance with the study of Mehrotra et al. $[39,40]$. In total 321 patients had buccal mucosa cancer: 191 (59.5\%) males and 130 (40.4\%) females. The predominant age group for this site involvement in our study was above 50 years (34.6\%). We observed a total of nine $(0.88 \%)$ patients who reported with the spread of cancer leading to involvement of skin along with buccal mucosa. Similarly, buccal vestibule is a common site to be affected by carcinoma. According to our data, $8.82 \%$ of oral cancer patients were diagnosed as isolated buccal vestibule carcinoma, with $60 \%$ being males and $40 \%$ females. Patients above 50 years of age were the ones that were most commonly affected. The rampant use of chewable tobacco can be linked to the relatively high incidence of involvement of buccal tissues. Mucosal lesions located in the cheeks are more common in South Central Asia, possibly related to tobacco chewing habits [41]. A study showed that Asians are more likely to develop malignancies in the buccal mucosa [1], a reflection of continuing areca and tobacco chewing habits. The higher rate of buccal carcinoma in Pakistan is likely related to the widespread practice of betel nut chewing and snuff-dipping and very rare alcohol intake [42]. $21.5 \%$ of the population in our study were seen to be affected by carcinoma of the mandibular alveolus, which is the second most common site involved. Out of a total of 220 patients, 138 (62.8\%) were males and 82 (37.2\%) were females. The peak incidence of $45 \%$ was observed in the age group of above 50 years. The posterior mandible was the predominant site. This was in accordance with the study of Yoshikazu et al. (1994) [43] in which 39 cases of primary intra-osseous carcinoma were reviewed. The mean age of patients was 51.0 years, and the $M$ : F ratio was $2: 3$. Lesions occurring in this region sometimes extend through the alveolar crest and lingual cortex, and spread through the inferior alveolar canal $[44,45]$ to involve the retromolar trigone, which is an ill-defined triangular area in the oral cavity posterior to the upper and lower third molar teeth with maxillary tuberosity at its apex. It is a relatively uncommon site for oral cancer [46]. We encountered $2.74 \%$ of patients with carcinoma of the retromolar trigone.

In our study, the third most commonly involved anatomical site observed was the lateral border of the tongue (19.21\%). Men were more commonly affected (79\%) than females (20.9\%). The peak incidence was observed in the age group of 31-40 years (33.2\%). In western countries, the oral tongue is the most common sub-site for OSCC in every race/ethnicity. It is more frequent among Filipino and Chinese women than men [41]. In a study of 108,780 cases of OSCC, the most common anatomical site $(n=44,072$; 41\%) was the tongue [47]. In India, besides betel-quid chewing, trends of alcohol consumption show an increasing intake in recent decades, a sign of the westernisation of cultural habits that influence OSCC incidence. Smoking and drinking are both inversely related to socio-economic status $[48,49]$. Financially deprived people have difficulties having a diet rich in fresh vegetables and fruit, reported as a protective factor [50]. Because of lack of knowledge and information, people of low socio-economic status are less aware of the outcomes of their customary habits, and problems in accessing healthcare facilities are related to poor oral health, which increases the oral cavity cancer risk [51]. This explains the high incidence of tongue cancer in the low socioeconomic population group of our study.

Squamous cell carcinoma of hard palate and maxillary alveolar ridge could be considered as a single site because the two areas are adjacent anatomically and share similar clinical presentation and management; however, in our study we have considered both palate and maxillary 
alveolus as separate entities for site specificity. Squamous cell carcinoma of the maxillary alveolus and hard palate is relatively uncommon in western society $[52,53]$. Petruzzelli and Mayers (1994) noted that neoplasia of the upper jaw constitutes only $2 \%$ of all head and neck malignancies and $10 \%$ of oral cancers [54]. The lesion appears to be more common in India, accounting for $40-55 \%$ of oropharyngeal cancers [55]. 5.29\% of oral cancer patients in our study were diagnosed as cases of isolated palatal cancer, with the highest observed incidence in the age group of above 50 years (55.5\%). Out of a total of 54 patients, $33(61.1 \%)$ were males and 21 (38.8\%) were females. In cases of carcinoma of maxillary alveolus, $4.41 \%$ of patients were recorded to be affected, and the majority of patients (66.6\%) belonged to the age group of above 50 years. As in palatal carcinomas, cancer of the maxillary alveolus was seen to predominantly affect males (40\%) rather than females (60\%). Smoking is considered to be the most common risk factor for palatal carcinomas. The male predominance of palatal cancer in our study is explained by the greater indulgence by men. This is in accordance with study of Lihua et al. in 2008, in which the Chinese reported the highest $M: F$ ratio of $3: 1$ [41]. However, in the Philippines reverse smoking is a common practice among women. Palatal OSCC cases were found in 17 Filipino females and just in one male in a study conducted in California [56, 57]. As compared with conventional smoking, reverse smoking involves putting the lit end of a cigarette inside the mouth.

According to our data, $2.35 \%$ cases were reported as carcinoma of the lower lip. Out of a total of 24 cases, 18 (75\%) were male and six (25\%) were female. No case of upper lip carcinoma was reported. The peak incidence of lower lip cancer in our study was seen in the age group of above 50 years. This was in accordance with a retrospective study of 184 patients with squamous cell carcinoma of the lower lip, in which 166 (90.2\%) men and 18 (9.8\%) women, with a mean age of 66 years, was reported [58]. The male predominance could be explained by the fact that their indulgence in outdoor activities is greater in comparison to females. A risk factor associated with carcinoma of the lower lip, apart from tobacco chewing and smoking, is prolonged exposure to UV rays. Usually the lower lip is involved as it receives more direct sunlight [59]. In countries closer to the equator with regular long hours of sunshine, such as rural Greece, lip cancer accounts for $60 \%$ of oral cancer [60]. In our study, the majority of the population we encountered were rural people, mostly farmers, who work under direct sunlight throughout the day and thus are the ones most exposed to UV rays.

Oral cancer is a viscous disease that severely affects basic human living functions. It is estimated that around 43\% of cancer deaths are due to tobacco use, alcohol consumption, unhealthy diets, inactive lifestyle, and infection [61]. Of these, tobacco use is the world's most un-avoidable cause of cancer. It is a largely preventable disease through lifestyle choices that reduce one's risk for the disease. Relatively high usage of tobacco in rural areas has led to an increase in incidence, which, in combination with delayed presentation because of the unawareness of the initial presentation of cancerous lesions, irregular follow-ups, limited access to cancer care, lack of trained health care providers, and low financial status, has made oral cancer a challenging health problem in rural areas of India. Regular free screening camps should be organised to detect dysplastic lesions at an early age, and health care providers and diagnostic centres should be made available at short distances where regular health check-ups along with the counselling of poor uneducated people can be done and patients suffering from cancer can be referred to multidisciplinary hospitals where proper and definite care can be given.

\section{The authors declare no conflict of interest.}

\section{References}

1. International Agency for Research on cancer. The Agency, Lyon 2006.

2. Peterson PE. Oral cancer prevention and control. The approach of the World Health Organisation. Oral Oncology 2008.

3. Sankara NR, Ramadas K, Thomas G, Muwonge R, Thara S. Effect of screening on oral cancer mortality in Kerala, India: A cluster randomized controlled trial. Lancet 2005; 365: 1927-33.

4. Dikshit R, Gupta PC, Rama SC, Gajalakshmi V, Aleksandrowicz L. Cancer mortality in India: A nationally representative survey. Lancet 2012; 379: 1807-16.

5. Yeole B, Kumar RA, Sankara NR. Survival from oral cancer in Mumbai, India. Cancer 2003; 14: 942-52.

6. Chaturvedi AK, Eagels EA, Anderson WF, Gillison ML. Incidence trends for human papilloma virus-related and unrelated oral squamous cell carcinoma in the United States. J Clin Oncol 2008; 26: 612-9.

7. Diaz EM, Kies MS, Sturgis EM. Head and Neck Cancer Medicine. $7^{\text {th }}$ edition. BC Deckar; Hamilton, Ontario 2006; 1131-78.

8. Favero A, Conti E. Food groups, oils and butter, and cancer of the oral cavity and pharynx. Br J Cancer 1999; 80: 614-20.

9. Goldenberg DM. A risk factor for oral and oro-pharyngeal cancer. Oral Oncol 2002; 38: 646-9.

10. Guha N, Boffetta P, Wunsch FV. Oral health and esophagus: results of two multicentric case-control studies. Am J Epidemiol 2007; 166: 1159-78.

11. Blot WJ, Laughlin JK, Winn DM, Austin DF, Greenberg RS, Preston-Martin S. Smoking and drinking in relation to oral and pharyngeal cancer. Cancer Res 1988; 48: 3282-7.

12. Negri E, La VC, Franceschi S, Tavani A. Attributable risk for oral cancer in northern Italy. Cancer Epidemiol Biomakers Prev 1993; 2: 189-93.

13. Idris AM, Nair J, Friesen M, Ohshima H, Brouet I. Carcinogenic tobacco-specific nitrosamines are present at unusually high levels in the saliva of oral snuff users in Sudan. Carcinogenesis 1992; 13: 1001-5.

14. Nair J, Oshima H, Friesen M, Croisy A, Bhide SV, Bartsch H. Tobacco specific and betel nut specific $\mathrm{N}$-nitroso compounds: occurrence in saliva and urine of betel quid chewers and formation in vitro by nitrosation of betel quid. Carcinogenesis 1985; 6: 295-303.

15. International Agency on Research on cancer. IARC: Monographs on the evaluation of carcinogenic risks to Humans. IARC Press, Lyon 2004

16. Ogden GR. Alcohol and oral cancer. Alcohol 2005; 35: 169-73.

17. Figuero RE, Carretero MA, Cerero LR, Esparza GG, Moreno Lopez $L A$. Effects of the consumption of alcohol in the oral cavity: relationship with oral cancer. Med Oral 2004; 9: 14-23.

18. Chhetri DK, Rawnsley JD, Calcaterra TC. Carcinoma of the buccal mucosa. Otolaryngol Head Neck Surg 2000; 123: 566-71.

19. Diaz EM, Holsinger FC, Zuniga ER, Roberts DB, Sorensen DM. Squamous cell carcinoma of the bucal mucosa: one institutions experience with 119 previously untreated patients. Head Neck 2003; 25: 267-73. 
20. Iyer SG, Pradhan SA, Pai PS, Patil S. Surgical treatment outcomes of localized squamous carcinoma of buccal mucosa. Head Neck 2004; 26: 897-902.

21. Liao CT, Wang HM, Yen TC, Lee LY, Hsueh C. Good tumor control and survivals of squamous cell carcinoma of buccal mucosa treated with radical surgery with or without neck dissection in Taiwan. Oral Oncol 2006; 42: 800-9.

22. Lin CS, Jen YM, Chang MF, Lin YS, Hwang JM. Squamous cell carci noma of the buccal mucosa: an aggressive cancer requiring multimodality treatment. Head Neck 2006; 28: 150-7.

23. Luis A, Adriana P, Daniel R. Trends in frequency and prevalence of oral cancer and oral squamous cell carcinoma in Mexicans. A 20 years retrospective study. Med Oral Patol Oral Cir Buccal 2011; 16: 1-5.

24. Phillips PA. The basic science of oncology. Pergamon Press, New York 1987; 25

25. WHO, World Health Statistics Annual. Geneva, WHO 1987.

26. Annertz K, Anderson H, Biorklund A, Moller T, Kantola S. Incidence and survival of squamous cell carcinoma of the tongue in Scandinavia with special reference to young adults. Int J Cancer 2002; 101: 95-9.

27. Macfarlane GJ, Boyle P, Scully C. Rising mortality from cancer of the tongue in young Scottish males. Lancet 1987; 17: 912.

28. Schantz SP, Yu GP. Head and neck cancer incidence trends in young Americans,1973-1997, with a special analysis for tongue cancer. Arch Otolaryngol Head Neck Surg 2002; 128: 268-74.

29. Wanakulasuriya S, Mak V, Moller H. Oral cancer survival in young people in South East England. Oral Oncol 2007; 43: 982-6.

30. Llewellyn CD, Johnson NW, Warna KA. Risk factors for oral cancer in newly diagnosed patients aged 45 years \& younger: a case-control study in Southern England. J Oral Pathol Med 2004; 33: 525-32.

31. Chow CW, Tabrizi SN, Tiedemann K, Waters KD. Squamous cell carcinomas in children \& young adults: a new wave of a very rare tumor. J Pediatr Surg 2007; 42: 2035-9.

32. Dahlstrom KR, Little JA, Zafereo ME, Lung M, Sturgis EM. Squa mous cell carcinoma of the head \& neck in never smoker-never drinkers: a descriptive epidemiologic study. Head Neck 2008; 30: 75-84.

33. Shiboski CH, Schmidt BL, Jordan RC. Tongue and tonsil carcinoma: increasing trends in the U.S. population ages 20-44 years. Cancer 2005; 103: 1843-9.

34. Hirota SK, Braga FP, Penha SS, Sugaya NN, Migliari DA. Risk factors for oral squamous cell carcinoma in young and older Brazilian patients: a comparative analysis. Med Oral Patol Oral Cir Bucal 2008 13: E227-31.

35. Pathak KA, Gupta S, Talole S, Khanna V, Chaturvedi P, Deshpande MS. Advanced squamous cell carcinoma of lower gingiva-buccal complex: Patterns of spread and failure. Head Neck 2005; 27: 597 602.

36. Watkinson JC, Gaze MN, Wilson JA. Tumors of the lip and oral cavity. In: Stell and Maran's Head \& Neck surgery. Butterworth-Heinemann, Oxford 2000; 275-318.

37. Rivera H, Nikitakis NG, Correnti M, Maissi S, Ponce JG. Oral and oropharyngeal cancer in a Venezuelan population. Acta Odontol Latino Am 2008; 21: 175-80.

38. More Y, D'Cruz AK. Oral cancer: Review of current management strategies. Natl Med J India 2013; 26: 152-8.

39. Mehrotra R, Singh M, Gupta RK, Singh M, Kapoor AK. Trends of prevalence and pathological spectrum of head \& neck cancers in North India. Indian J Cancer 2005; 42: 89-93.

40. Kumar S, Heller RF, Pandey U, Tewari V, Bala N. Delay in presentation of oral cancer: a multifactor analytical study. Natl Med I India 2001; 14: 13-7.

41. Liu L, Kumar SK, Sedghizadeh PP, Jayakar AN, Shuler CF. Oral squamous cell carcinoma incidence by subsite among diverse racial and ethnic populations in California. Oral Surg Oral Med Oral Pathol Oral Radiol Endod 2008; 105: 470-80.

42. Essig H, Warraich R, Zulfiqar G, Eckardt A. Assessment of cervical lymph node metastasis for therapeutic decision-making in squamous cell carcinoma of buccal mucosa: a prospective clinical analysis. World J Surg Oncol 2012; 10: 253.
43. Yoshikazu S, Keiji T, Taguchi A, Takuro W. Primary intraosseous carcinoma: Review of literature and diagnostic criteria. J Oral Maxillofac Surg 1994; 52: 580-3.

44. Huntley TA, Busmanis I, Desmond P, Wisenfeld D. Mandibular invasion by squamous cell carcinoma: a computed tomographic and istological study. Br J Oral Maxillofac Surg 1996; 34: 69-74.

45. Browns JS, Lowe D, Kalavrezos N, D'souza J, Magennis P, Woolger J. Patterns of invasion and routes of entry into mandible by oral squamous cell carcinoma. Head Neck 2002; 24: 370-83.

46. Binahmed A, Nason RW, Abdoh AA, Sandor GKB. Population-based study of treatment outcomes in squamous cell carcinoma of the retromolar trigone. Oral Surgery, Oral Medicine, Oral Pathology, Oral Radiology and Endodontology 2007; 104: 662-665.

47. Cancela M, Votil L, Guerra M, Chapuis F, Mazuir M. Oral cavity cancer in developed and in developing countries: population-based incidence. Head \& Neck 2010; 10: 1002.

48. Stellman SD, Resnicow K. Tobacco smoking, cancer and social class. IARC, Lyon 1997.

49. Moller H, Tonnesen $\mathrm{H}$. Alcohol drinking, social class and cancer. IARC; Lyon 1997.

50. Pavia M, Pileggi C, Nobile CG, Angelillo IF. Association between fruit \& vegetable consumption and oral cancer: a meta-analysis of observational studies. Am J Clin Nutr 2006; 83: 1126-1134.

51. Guha N, Boffetta P, Wunsch FV. Oral health and risk of squamous cell carcinoma of the head \& neck and oesophagus: results of two multicentric case-control studies. Am J Epidemiol 2007; 166: 1159 73

52. Bhansali S. Malignant tumors of the buccal cavity: a clinical analysis of 970 cases. Clin Radiol 1961; 12: 299-308.

53. Krolls S, Hoffman S. Squamous cell carcinoma of the oral soft tissues: a statistical analysis of 14,253 cases by age, sex, \& race of the patients. J Am Dent Assoc 1976; 92: 571-4.

54. Petruzelli G, Mayers E. Malignant neoplasms of the hard palate and upper alveolar ridge. Oncology 1994; 8: 43-48.

55. Ramulu C, Reddy C. Carcinoma of the hard palate and its relation to reverse smoking. Int Surg 1972; 57: 636-40.

56. Mercado OG, Wilson D, Jiang DJ. Reverse smoking and palatal mucosal changes in Filipino women - epidemiological features. Aust Dent J 1996; 41: 300-3.

57. Ortiz GM, Pierce AM, Wilson DF. Palatal changes associated with reverse smoking in Filipino women. Oral Dis 1996; 2: 232-7.

58. Vischer JG. Surgical treatment of squamous cell carcinoma of lower lip: evaluation of long term results \& prognostic factors a retrospective analysis of 184 patients. J Oral Maxillofac Surg 1998; 56: 814-20.

59. Baker SR, Krause CJ. Carcinoma of the lip. Laryngoscope 1980; 90: 19-27.

60. Antoniades DZ, Papanayotou P, Trigonidis G. Squamous cell carcinoma of the lips in a northern Greek population. Evaluation of prognostic factors on 5 year survival rate-I. Eur J Cancer B Oral Oncol 1995; 31(B): 333-339.

61. Lopez AD, Mathers CD, Ezzati M, Jamison DT, Murray CJL. Global burden of disease and risk factors. The World Bank/Oxford University Press, Washington 2006.

\section{Address for correspondence}

\section{Parul Tandon}

PMT LONI

413736 Loni, India

e-mail: parul.tandon12@gmail.com

Submitted: 25.03 .2016

Accepted: $\quad 30.09 .2016$ 